\title{
Particularities of Education Based on Competences in the Online Environment - Qualitative Study
}

\author{
Mihaela Prună ${ }^{1}$ \\ ${ }^{1)}$ Romanian-American University, Bucharest, Romania. \\ E-mail: mjitea@yahoo.com
}

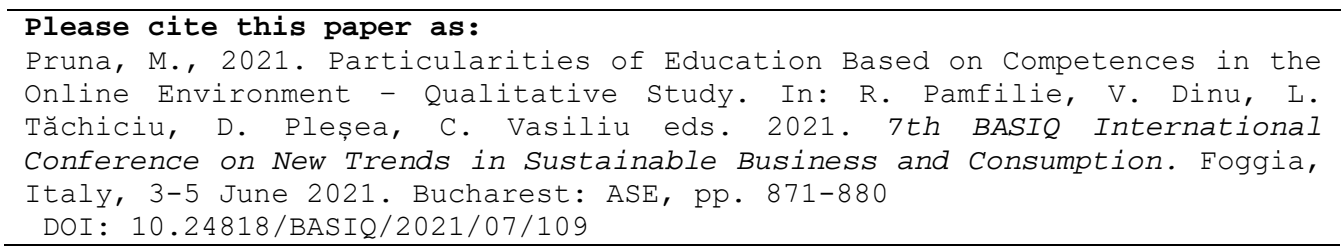

\begin{abstract}
In this scientific study, the author slots to identify the particularities of online learning within the framework of competence-based education. The intention is to analyze the specifics of online learning when it is a predominant and independent method in competent education and not a complementary one in the case of distance learning. After a brief historical analysis of pedagogical systems based on content, objectives and competences, the author analyses the impact that the key competences promoted at EU level. The analysis allows it to emphasize the importance of key competences by their purpose, which lies not only in the act of learning but also in the act of turning into practice. The COVID-19 has made the most of the proficiency-based pedagogy in both the university and the pre-university environment. Based on a quality study, using the Delphi method, the author used two samples to identify these particularities. In the first part of the study in relation to the specifics of competence-based learning, the author identified the top 12 aspects of learning that online are harder for teachers to achieve. Both categories of respondents (from academia and preuniversity) identified the same aspect in a group of 12 . Using the results of the research and professional experience the respondents were asked to identify the main characteristics of the virtual class and to put them in correspondence with the characteristics of the real class. The group of 10 identified characteristics was similar to the 2 learning environments. In the second part of the study a number of 50 respondents, divided equally in university and pre-university were asked to respond on a scale of 1 to 10 which is the negative impact of each characteristic of the virtual class previously identified. The result shows differences between two categories of respondents, which were interpreted in the study.
\end{abstract}

\section{Keywords}

competence-based education, predominant online learning, undefined physical space, competent key.

DOI: 10.24818/BASIQ/2021/07/109

\section{Introduction}

The term education comes from the noun education, which means growth, feeding, cultivation. As meaning, the purpose of education is to prepare man as an active element of social life, to transform him into a socially proactive actor, able to support society and help develop it. As a philosophy of action, education is an intervention or targeting, a tool for socializing and ensuring balance and social dynamics.

From this recital we understand that education does not refer strictly to education received in school, to teaching education but ultimately refers to the development of a general culture and learning and the promotion of moral values capable of developing conformism and creativity, order and spontaneity, discipline and flexibility. That's why F. Skinner said that education is "what survives after everything that has been learned has been forgotten" (Skinner, 1976). 


\section{BASIQ INTERNATIONAL CONFERENCE}

In this scientific study we will analyze the term education in the sense of didactic education. As a field of knowledge, even as a science, education is the fundamental concept used in pedagogy. Pedagogy studies and proposes the most effective educational systems, so that the student receives an education as close as possible to its general meaning, in terms of teaching, learning, evaluation, support including socio-emotional education, as defined by the OECD, encompassing the ability to manage a person's thoughts, emotions and behavior that enable them to understand and manage their emotions, set goals, show empathy for others, establish positive relationships and make responsible decisions.

To what extent does teaching education prepare the student as a proactive social actor? What should such an educational system look like? These are the questions and ambition of any effective and effective pedagogical system. Without going into a historical analysis of pedagogy let's say that three answers were considered the most important. Content-centered education that involved the transmission/assimilation of verified knowledge, as comprehensive and qualitative as possible and diversified. It was also called encyclopedic education because of the claim to transmit all the significant knowledge that existed at one time.

This type of education has been overcome by goal-oriented education. Bloom, (1956), through the taxonomy of educational objectives, gave a significant impetus to this type of education. It was the stage in which psychology had a hard word to say through components and dimensions of individualized learning psychology applied to the design, organization and evaluation of the educational process. By operationalizing the objectives (Mager) it was possible to describe the pursued behaviors. The formalism and the excessive focus on the efficiency of the operationalization slowly transformed the didactic approach into a scholastic one, moving it away from reality.

Since the last part of the last century (after 1980), the finalities of the training process go beyond the area of objectives and move to the area of skills, as a result of the development of cognitive concepts, according to which information processing leads to the formation of skills. The purpose of education in general, but also of the educational process in particular, will be based on skills so that the learning of knowledge is matched by their transfer to everyday life. In theory, pedagogy embraces the sociological conception of society, more comprehensive than the psychological one, pedagogy becoming social and promoting the idea that education systems must make it possible to transfer knowledge into everyday life, the educational act having to make the transition from the instructive dimension to the humanistic (functional) dimension, to functional literacy, which allows the optimal transfer of knowledge and values from one generation to the next.

\section{Skills-based education and effective social integration}

Skills-based education is currently in the midst of theoretical disputes far from ending. I will translate into a pedagogical context, the definition of competence formulated by the "Recommendation of the European Parliament and of the Council of 23 April 2008 (Official Journal of the European Union C 111 of 6.05.2008) and also mentioned in Law 1/ 2011 (National Education Act), as representing the student's proven ability to select, combine and use adequately, knowledge, skills, values and attitudes, in concrete situations, in order to achieve an effective and effective learning task. From the perspective of the educational process, competence can be considered as an actionable availability of the student, based both on prior experience and as a potential that must be translated into practice in concrete situations. In this logic, the pedagogical approach must be analyzed. Moreover, two issues need to be clarified before this type of education can be promoted.

A. On the one hand, to what extent is it realistic to talk about skills training from a pedagogical perspective, in other words is it possible to build a plan, a mental map containing the most appropriate content of learning? That is, a competency-based curriculum. What is in it about entrepreneurial competence? What content - knowledge, skills, values and attitudes - comprises in such a way as to define entrepreneurial competence?

The problem of the curriculum is as important as the education system, and each of the educational systems mentioned - content, objectives and competences - had in the alternative concrete content. In 
building an information society or a knowledge society, the question of choosing the content of education becomes a strategic one.

The need for changes in learning content is determined by the emergence of new educational needs (Braslavsky, 2001). We can talk about a paradigm shift at the social level. The society of 30-40 years ago was founded on the paradigm of information accumulation. This involved adding as much information as possible (quantity was the main structuring indicator). Today this paradigm is outdated. What we need to do today is to filter to synthesize, a paradigm of information synthesis (with emphasis on its quality) is what we need to systematically follow. The social actor is facing diversity, over-information (see social media and smart phone), the growth of the public area that attacks the private area using questionable ethics.

These problems oblige education researchers, as well as decision-makers, to redefine the meaning of education, the structure of the education system, the content and methods of education. The new content must be able to help the student integrate both professionally and into everyday life. This pedagogical road is called the scientific curriculum. In a daily sense, the curriculum is a path that the student has to go through during the schooling period, day by day.

In a historical analysis there are two different perspectives in the conception of the notion of curriculum. The first perspective, which dominates goal-centered education systems, is technical and planning (Tyler, 1949). The perspective involves defining, within the framework of the curricula, objectives, including their operationalization, which divide teaching-learning activities into microunits and generate pedagogy through objectives.

The second perspective is inspired by the works of Lawton (1983) and is called a humanistic (sociocultural) approach to the curriculum. According to this approach, an individual can humanize and socialize only by becoming a member of a social group and sharing the culture, language and experience of other members of the group. From this perspective, the curriculum should allow the student to be opened up to others and to society in general, by appropriating the right knowledge and experiences in the form of competences - pedagogy through competences.

From the point of view of structure, multifunctional analysis of the notion of "curriculum" integrates the answers to all the questions that can be formulated regarding the act of learning (derived from the classic questions of the communication process, starting from the idea that learning is basically a communication): why? (meaning, values, functions), who? (characteristics of the subject of learning), what? (content), when? (time), how? (learning strategies), under what conditions? (learning situations, materials used) and with what effect? (expected results) (Walterova, 1991).

From a functional point of view, pedagogical practice has led to the emergence of complex, dynamic curricular content centered on skills management, student/student needs, proactivist, multidisciplinary and ness and knowledge, including cross-cutting skills and contextual learning as part of the skills system.

Of these, the focus of education on the student has become important in a knowledge society. No matter which methods they prefer, students should be active when searching for knowledge. They should research and explore the issues on their own through the studio individually or in the work teams. This will help them accumulate the knowledge they need to prepare for future use. Even when there is a change in the knowledge needed, perhaps as a result of technological advances, they will still be able to adapt and work just as effectively. Full education is the one that can harness the potential of students. Education must provide them with the necessary conditions to discover their calling, to do what they are interested in and what they can do best.

Competence-based education systems will only be able to prove their pragmatism in complementary (formal, nonformal, informal) and contextual contexts only if certain conditions are met cumulatively. First, the competences that the student must prove at the end of each school year, at the end of a school cycle, and at the end of the curricula are clearly defined. Secondly, the teacher's work should focus less on designing and more on the organization and coordination of learning, (including feedback). Thirdly, the student must prove that he knows how to use and apply, which he learns, both in a professional context and in everyday life. Skills pedagogy must give a pragmatic/functional 
meaning to learning, facilitating real learning contexts, whereby the student is motivated that everything they learn is useful to him.

Fourthly, competences should no longer be regarded as a sum of knowledge, skills and attitudes, but as the result of their combined application to solve concrete situations. This will allow, very important in the logic of the pedagogy of competences, the integration of socio-emotional skills in educational design;

B. On the other hand, what powers would it contain? What would be the most important skills we need to focus on so that we can prepare the student for professional and daily life?

Key competences as recommended by the European Union (2006):

Key competences are a cumulation of knowledge, skills and attitudes that all individuals need for personal development and development, to socialize and for their professional career.

They must be developed until compulsory education is completed and must act as a foundation for further learning as part of lifelong learning. The eight key competencies are:

- Communication in the mother tongue.

- Communication in foreign languages.

- Mathematical competence and basic skills in science and technology

- Digital competence.

- The competence to learn to learn.

- Social and civic skills.

- The spirit of initiative and entrepreneurship.

- Cultural awareness and expression.

All these key competences are interdependent, and the emphasis in each case is on critical thinking, creativity, initiative, problem solving, risk assessment, decision-making and constructive management of feelings.

\section{Skills-based education in the online space. Qualitative study}

Online learning is usually understood as education that takes place on the internet. It can be part of distance education programs, but it can also be used to complement the teaching that takes place in the classroom. As a complementary form, online skills-based education is based on the whole instrumentation as well as learning techniques and curriculum logic specific to competence-based learning. Although certain peculiarities arise generated strictly by teacher-student/student communication online, as long as it remains a complementary technique, its impact remains small.

Significant changes in online education occur to the extent that this type of education becomes somewhat independent and self-contained, as was the case last year due to the Covid pandemic 19. The scientific study underlying the article takes into account this situation. Two qualitative studies have been conducted that analyze how competence-based education supports significant features insofar as online learning becomes the main or even the only one after which evaluations are made and class performance is analyzed.

In the first study we asked 40 teachers (teachers) from pre-university and university education, based on the logic of skills-based education - the content of learning (the curriculum) - to mention those aspects that are difficult to manage from the perspective of online education. I made sure that all respondents had taught in the last year online, as the predominant technique opposite the subjects taught. We used a simple Delphi questionnaire - one open question - which are in your opinion the difficult-to-manage aspects in the online system and which are specific to skills-based learning. I used a single structuring question - pre-university or university. I did not take into account either the seniority in education or their possible digital skills acquired previously. In order of their 
identification by the respondents, the top 12 are shown below - Difficult to manage aspects of online education, Support for students with learning disabilities, Direct human relation (teacher-student and student-student interpersonal communication), Monitoring learning progress, Feedback to correct some aspects of learning, Individual focused counseling, Constant attention to hours, Lack of digital educational content, Direct didactic control, Managing disruptive factors, Manage motivation in class, Limits due to the specifics of the disciplines, Limited powers to use platforms.

\section{Support for students with learning disabilities}

Competence-based education enables support for students with learning disabilities by providing a somewhat secondary path, easier transmission of content or the use of less abstract language. This is much harder to achieve online and requires a much greater effort on the part of the teacher.

\section{Direct human relation}

An extremely important issue in skills-based education is almost completely losing its effect. Media mediation, even video, cannot replace face-to-face communication, in terms of attention, presence of mind, affectivity and information exchange. This applies to both type communications teacher/student/student and student/student - student/student. Management of nonverbal communication, dynamic dialogue, spatial positioning of those who communicate are important elements in the economy of the game that in online teaching are very limited.

\section{Monitoring learning progress}

We are talking here about that continuous monitoring that takes place in the classroom through a rapid dialogue at the beginning of the classes, through the request for adhoc opinions, through the authority that the teacher exercises by his mere presence. Quick, short tests, sometimes with their quick resolution along with the class that marked an increased attention to monitoring the progress of learning are difficult to achieve in online learning.

\section{Feedback to correct some aspects of learning}

It is an important aspect of education based on competence and which is much harder to manage online. The overall picture that the teacher has in the class is important for feedback. Correcting less understood aspects, viewing other students, further approval feedback are time-consuming elements. Teachers insist on this subject, especially when they believe they have taught heavier elements. The fact that in online, argumentation, case study, paraphrases are less, focusing on synthesis, on the main ideas on important issues makes this aspect even more important.

\section{Individual focused counselling}

It is a tool by which the teacher is attentive to certain aspects of learning, which by monitoring progress requires additional individual clarifications. In face-to-face communication counseling is done much more easily, some teachers using certain downtimes in the program or staying at school after a certain planning. Today it is a tool that many teachers have given up due to pandemic conditions.

\section{Constant attention to hours}

It is a secondary activity that is carried out at the same time as teaching. The existence of the physical class, the direct authority of the teacher, the spatial arrangement of the banks (the u-system that allows everyone to see everyone), direct visual contact makes the attention to be maintained somewhat ad hoc. In online, besides the fact that these whistle-blowers disappear, other vulnerabilities related to video access appear, the presence of other people in the room, other devices that the student can use, etc. All of these result in diminished attention in online classes, which is reflected in the effectiveness of teaching listening.

\section{Lack of digital educational content}

It's a real problem, considering that online education was complementary to distance education. It takes time to structure efficient and functional digital educational content. PowerPoints, graphs, tables, classifications or other small summaries also have a minus. When used, the video connection 
between the teacher and the students is interrupted. These contents will require greater effort on the part of the teacher to conceive and realize them.

\section{Direct didactic control}

It's an important aspect in the physical class. The physical presence of the teacher, the visual contact, the adhoc correction of some behaviors, the identification of a state of fatigue, misunderstanding or non-involvement leads to the immediate change of the teaching strategy by short steps, paraphrasing, pointing out a main idea and arguing it. It's a strategic interruption of surrender to correct disruptive factors and gain control. This indirectly extremely important aspect through its effects is almost impossible to achieve in the virtual class.

\section{Managing disruptive factors}

A disruptive factor is a factor that has a negative influence on the learning process. In the practice of teaching, we encounter many disruptive factors, the important element in the physical class is its rapid identification and taking the necessary measures. Lack of notebook or writing tool, noninvolvement in dialogue, misunderstanding of a term, discussions between students, teasing of colleagues are elements that are corrected somewhat naturally. In the virtual class there are other factors, impossible to control and manage by the teacher. Perhaps the most important disruptive factor in the virtual class is the lack of video connection, which greatly decreases interest in the hour.

\section{Manage motivation in class}

This is more important than maintaining attention. The existence of motivation implies that the student wants to be effective in class. Due to psychological duplicity, it is easy to induce the idea that the student is in class, when in fact his mind is in a completely different place. The question of motivation is related to self-interest and depends very much on the will and choice of the student. In the physical class an experienced teacher can read students easily and can be able to figure out whether or not they are in the class mentally. In the virtual class this is done much harder. Ensuring motivation in class is really an important aspect in pedagogical practice and it is often many other aspects included in the learning process.

\section{Limits due to the specifics of the disciplines}

Each discipline has its own specificity. Humanistic disciplines that do not use a technical language are easier to teach. Technical or natural science disciplines that use planes, graphs or other visual instruments are harder to teach because they often stop interrupting by contact, visual and video.

\section{Limited powers to use platforms}

The digital competences of teachers and students also have an important role and little in the first months or in the first year, the lack of these competences will affect the effectiveness of online learning. To the extent that the software that will be built will be easy to use, they will be easily learned and these skills will be more and more efficient.

These 12 aspects captured in research will need to be analyzed by school management and IT specialists in order to find quick solutions for their efficient management.

It should also be remembered that between the university and the university there were no differences in the group of 12 aspects indicated. The scores obtained were slightly different but not significant enough to use them separately in research. The unmanageable aspects of online education in the two learning environments are significantly the same.

In phase two we asked the same sample to identify the main features and characteristics of the virtual class. They had at their disposal the results of the research in the first phase, coupled with their experience working with the class of students in the physical environment. In order to do a comparative socio-didactic analysis we also retained the correspondence of the trait or characteristic of the physical house. Data processing and analysis led to the following conclusions. 


\begin{tabular}{|c|c|}
\hline \multicolumn{2}{|c|}{ New Trends in Sustainable Business and Consumption } \\
\hline Real Class & Virtual Class \\
\hline Physical space defined & Undefined physical space \\
\hline Direct interpersonal communication & Indirect interpersonal communication \\
\hline Uninterrupted eye contact & Interrupted eye contact \\
\hline Direct control of students & Limiting student control \\
\hline Disruptive factors under control & Disruptive factors that are hard to control \\
\hline Teamwork & Strictly individual work \\
\hline Adhoc rating & Rating announced \\
\hline Direct interpersonal cooperation & Indirect interpersonal cooperation \\
\hline $\begin{array}{l}\text { Individualization and personalization of } \\
\text { learning }\end{array}$ & $\begin{array}{l}\text { Lack of individualization and personalization } \\
\text { of learning }\end{array}$ \\
\hline The socio-humanistic dimension of learning & Instructive dimension of learning \\
\hline
\end{tabular}

Defined physical space vs. undefined physical space

The first advanced feature was the difference between the physical space and the virtual class. Pedagogical practice uses the constituent elements of the physical space in the class as sources of attention-keeping. The existence of the board, the department and the banks have a direct impact in the learning process. Laboratories use much more varied elements besides those mentioned appear exposed on the walls important information for discipline or visual elements specific to the discipline, which have important impact in ensuring motivation. Physical space is well defined relative to the surface, bounded by other spaces which ensure beneficial intimacy. Virtual space is diverse, undefined, spatially scattered, undelimited. It has two small advantages - it is chosen by the student according to his desire and can be familiar to him.

\section{Direct interpersonal communication vs. indirect interpersonal communication}

I looked above at the impact of direct interpersonal communication, face to face. Probably the most effective way of teaching communication, in turn influences many other aspects of learning. Even if in the virtual class, through the video system, we can talk about face-to-face interpersonal communication, in reality this is much limited in relation to communication in the physical class. Lack of physical image, exchange of nonverbal impressions - gesture, mimicry, eye contact, look, smile, laughter, etc. - creates major differences between the two types of communication.

\section{Uninterrupted eye contact vs. interrupted eye contact}

The visual analyzer is the most important analyzer. Over $85 \%$ of the information the man receives through the see. In the practice of learning eye contact is extremely effective, for attention, understanding, solving of small divergences. Visual contact creates a psychological comfort, which in turn influences memory, attention affectivity. It is a feature that in the virtual class no longer has the same impact due to interruptions. Its absence creates an adhoc intimidated student who can become a vulnerability for teaching.

\section{Direct student control vs. limiting student control}

The pedagogical control of the students is as important as the eye contact. He relies on the authority of the teacher and the fact that they have the freedom to run the class as he sees fit. It is also based on the teacher's freedom of movement, which can decide at any time the time of the class, and can send any message he deems necessary. The humanistic dimension of education based on competence practically increases the authority and freedom of movement of the teacher. In online education this control is drastically limited due to the context. Even if freedom of movement and authority, theoretic, remain unchanged, the effects are entirely different due to lack of proximity. 


\section{Disruptive factors under control vs. disruptive factors hard to control}

In practical pedagogy, disruptive factors are all aspects that make learning difficult, jam or block. There are many, psychological, cognitive, affective, physical and the online learning environment adds other specific factors. A thorough study is needed to identify them and seek solutions to counter the negative effects. The integrative element remains the teacher who can manage and limit the action of these factors. Online teaching emphasizes their effect and limits the teacher's ability to manage them effectively.

\section{Teamwork vs. individual work}

One of the great advantages of competence-based education is teamwork and teamwork. Topics, projects and problems that are solved in a team have a different impact on students/students than individual ones, generating communication, cooperation, joint search for solutions, division of tasks, choice of persons with a role of verification or coordination. These things do not meet in individual projects. Online learning greatly limits this kind of projects, being preferred individual ones, flesh and in the form of projects

\section{Adhoc rating vs. evaluation announced}

Adhoc or direct evaluation is an effective tool in education based on competence. In the form of questions, exchange of ideas or rapid tests, it is important for monitoring progress, correcting some aspects of less understood learning or simply for evaluation along the way. In online learning, although theoretically it can be yes, they are exempted due to the context, going on announced evaluations.

\section{Direct interpersonal cooperation vs indirect interpersonal cooperation}

The didactic interpersonal cover covers the broad process of communication and action together to cover all the problems generated by learning. Since education based on competence has a practicalfunctional, cooperation becomes important in projects aimed at working in a team or in the dialogue generated by the practicality of everyday life of assimilated competences. Cooperation is an indicator of social life and a psychological indicator in the sense that each individual has a personalized measure of interpersonal cooperation in the form of a skill, ritual or detailed mental map. All people cooperate, for some this is a threat to others is an opportunity. A didactic approach that promotes cooperation, such as learning through competence, has the advantage of polishing the cooperation of the student, to highlight it and to put it in agreement with the cell cooperation. In online learning this is no longer manifested, cooperation is much limited.

\section{Individualization and personalization of learning vs. lack of individualization and personalization of learning}

Personalized learning is an important dimension in skills-based education. How the transfer of competences in everyday life is done subjectively, people encounter personal hardships that require personalized answers. For this reason, both the assimilation of competences and their transposition into real life, requires increased communication with those who encounter difficulties and cannot use the standard model. These deviations are not exceptions for this type of learning, on the contrary it is accepted the idea that custom horses must be found whenever contextually requires it. It is an important aspect that suffers greatly in online learning. That's because it often takes a certain discretion, a certain pedagogical intimacy to assimilate the need for knowledge that online space does not offer.

\section{The socio-humanistic dimension of learning vs. the instructive dimension of learning}

Focused on competences, a cumulation of skills, knowledge and attitudes, learning has a deeply socioumanista character, because it cultivates in students the need to be a socially proactive actor that promotes balance and social order. The humanist dimension also resides in entrepreneurial or civic competences, related to spiritual initiative or social. The socioumanista dimension is more easily achieved in face-to-face, direct communication, in order to track the student's feedback, and better manage the needs of the receiver (student/student). In the online environment the dimension is rather 
instructive and this will put its mark on the transposition into the practice of life of assimilated competences.

An important aspect of the research was that the respondents in the two groups stopped at the same 10 important characteristics of the virtual class, which we identified as small differences resulted from the number of choices for each feature. In order to try to rank these characteristics according to their impact on online education, however, I asked for another sample consisting of respondents from the pre-university or university environment, in number of 50 subjects divided equally to give a score of 1 to 10 for each trait depending on the importance and negative impact it has in effective online learning, where 1 represents a very small negative impact, and 10 represents a very large negative impact.

These are - Undefined physical space, Indirect interpersonal communication, Interrupted eye contact, Limiting student control, Disruptive factors that are hard to control, Strictly individual work, Rating announced, Indirect interpersonal cooperation, Lack of individualization and personalization of learning, Instructive dimension of learning.

Hierarchy of virtual class traits according to their negative impact on competency-based learning. The processing and analysis of data for the 2 categories of respondents highlighted the following aspects.

\section{A. Respondents from the pre-university environment}

The characteristics with the greatest negative impact on the learning process were in order - the undefined physical space, with an average score of 9.5, limiting student control, score 9.3, disruptive factors difficult to control, 9.00, interrupted interpersonal communication, 8.4.

The lowest negative impact characteristics were the instructive dimension of learning, score 6.0, announced evaluations, 6.3, strictly individual work, 6.7 and indirect interpersonal cooperation, score 7.1 .

From the analysis of the data we understand that for the respondents in the pre-university environment the very large impact is given by the undefined physical space, followed by the limitation of control, disruptive factors and interrupted communication, characteristics that indicate both a pressure of the workspace and the possibility of manifestation of the teacher's authority, especially by lack of control.

The characteristic with the least impact is the instructive dimension, announced evaluations, individual work and cooperation, which indicates a teacher's focus on the more formal aspect of teaching, evaluations, individual work and a lower impact of cooperation.

The overall average score (the one that shows overall negative impact) is 7.7.

\section{B. Responses from academia}

Characteristics with the greatest negative impact were in order undefined physical space, score 9.7, indirect interpersonal cooperation, score 9.3, interpersonal communication indirect, score 9.2 and evaluations announced, score 9.

The characteristics with the least negative impact were in order limiting the control of the students, score 6.2, lack of individualization and customization of learning score 7.1, factors perturbator difficult to control, score 8.6 and interrupted eye contact 8.7 .

From the analysis of the data we understand that even for respondents in the physical space university environment undefined remains the characteristic with the greatest negative impact. The rest of the characteristics are related to a proactive teaching approach which at the moment is more difficult to achieve, I am referring here to cooperation, communication and announced evaluations, which are probably not specific to the university environment.

The characteristics with the lower impact are those that are not really used by teachers or student control, lack of individualization, disruptive factors or eye contact.

The average overall score was 8.5 . 


\section{BASIQ INTERNATIONAL CONFERENCE}

\section{Conclusions}

The findings of the research contained in the scientific study show important things that are worth highlighting.

First of all, online learning has a particular aspect that endangers the effectiveness of competent learning. Both categories of respondents have close answers. Moreover, the pedagogical aspects that are much harder to follow in this situation are the same in a group of 12 identified. What differentiated the respondents' responses were the number of choices for each aspect but the very small difference led me not to give them a meaning in the study

Secondly, the identification of the characteristics of the virtual class highlighted the same situation. Respondents in both categories identified a group of 10 features that they found important for the virtual class. The identification of these characteristics shows that in both categories - pre-university and university, the characteristics of a virtual class are similar. Mirror identification of the characteristics of the physical class gave me the opportunity to do a comparative socio-didactic analysis of these characteristics.

Thirdly, I wanted to analyze the negative impact of the characteristics of the virtual class from the point of view of the subjects. Here the results were more differentiated as follows:

- Respondents in the university environment feel in a stronger manner the negative impact of the characteristics of the class, overall score, 8.5, compared to those in pre-university, 7.7; even though both categories still perceived a high negative pressure, 7.7 and 8.5 on a scale of 1 to 10 , so greater than $75 \%$. This shows the weight faced by teachers in both teaching backgrounds;

- The undefined physical space (lack of physical class with its advantages) was considered the characteristic with the highest pressure of both categories of respondent;

- Those in academia consider the characteristics with very high negative impact as those that no longer allow dialogue, teamwork, active and two-way teaching. The least impact has the somewhat training characteristics related to student control or individualization of learning;

- Those in the pre-university environment consider that the greatest negative impact is the characteristics that refer to the authority of the teacher, especially by lack of control and direct communication or disruptive factors difficult to define. The least negative impact is the characteristics that indicate a certain formalism of teaching, especially by the instructive dimension and the announced evaluations or by indirect cooperation.

As a general conclusion, online learning as a predominant and independent technique raises a number of obstacles when it comes to education based on competence in both learning environments university and pre-university. Whether we are talking about some aspects specific to competencebased pedagogy that can no longer be carried out in optimal conditions, or characteristics of the virtual class that have a strong negative impact in the efficient conduct of the learning process.

\section{References}

Bloom, B., 1956. Taxonomy of Educational Objectives. London: Addison-Wesley Longman Ltd. Braslavsky, C., 2001. Tendences mondiale et developpment des curricula. Bruxelles: AFEC.

European Union, 2006. Recommendation of the European Parliament and of the Council of 18 December 2006 on key competences for lifelong learning.

Lawton, D.,1983. Curriculum Studies and Educational Planning. London: Hodder and Stoughton.

Mager, R., 1962. Preparing Instructional Objectives: A Critical Tool in the Development of Effective Instruction. New-York: Center for Effective Performance, USA.

Skinner, B. F., 1976. About Behaviorism. Boston: Ed. Vintage.

Tyler, R.W., 1949. Basic Principles of Curriculum and Instruction. Chicago: University of Chicago Press.

Walterova, E., 1991. Curriculum development in Czechoslvakia. Lyngby: Scandinavian Seminar of IMTEC. 